International Journal of English Literature and Social Sciences
Vol-6, Issue-3; May-Jun, 2021

Peer-Reviewed Journal

\title{
A review on college transfer majors and their English learning motivations
}

\author{
Zhang Jingyi ${ }^{1}$, Peng $\mathrm{Yi}^{2 *}$
}

\author{
${ }^{1}$ Zhang Jingyi is a postgraduate of QX191 in the School of Foreign Studies, Yangtze University, China \\ ${ }^{2}$ Associate Professor in the School of Foreign Studies, Yangtze University, China \\ *Corresponding Author
}

Received: 30 Mar 2021; Received in revised form: 05 May 2021; Accepted: 25 May 2021; Available online: 05 Jun 2021 (C2021 The Author(s). Published by Infogain Publication. This is an open access article under the CC BY license (https://creativecommons.org/licenses/by/4.0/).

\begin{abstract}
In recent years, more and more universities pay more attention to the improvement of college students' education quality, have carried out undergraduate teaching reform. Among them, the implementation of the major transferring of college students has been a highlight in the current university undergraduate teaching reform. Meanwhile, English learning motivation is one of the most important factors that affect the English learners' learning achievements. How to cultivate and stimulate English learners' motivation has been concerned by the English teachers and researchers at home and abroad nowadays. On the basis, this article reviews domestic and foreign researches on college students' major transferring and their English learning motivation, expect to bring enlightenment for the further research.
\end{abstract}

Keywords-Major transferring; College students; English learning motivation.

\section{RESEARCH BACKGROUND}

Every September, high school graduates who have successfully passed the college entrance examination enter the university with full expectations for their future study and life.At present, the scores of college entrance examination and the fractional line of each university and major are the primary basis for college students to choose their major before entering school. Using the sentence "one test for life" to describe the college entrance examination is absolutely appropriate. This may be because students choose schools and majors after the examination, which will greatly affect their future career development and life planning. However, after a period of university life, some students discovered the majors and courses they actually studied were completely different from what they had imagined before entering the school. Gradually, these students began to dislike the major they were studying, their learning potential was restricted, and the idea of transferring to another major began to sprout.

Under the circumstances of more and more students want to transfer majors, lots of colleges begin to implement relevant policies, allow students to transfer majors. This will provide students with the opportunity to choose their major again, breaking the rigid system of "one-stroke life ". At the same time, through the independent choice of major, students can be promoted from passive learning to active learning, improve their enthusiasm for learning, and can also promote the reform of teaching management in higher schools. It is a kind of progress that colleges allow students to transfer major, which well embodies the idea of "people-oriented" in today's universities, and also embodies the respect of students' right of choice, development and study, and is also conducive to the allocation of social talent resources. 
In addition, allowing students to transfer majors can also promote the construction and reform of disciplines and specialties inuniversities, because if colleges want to reduce the loss of students, they must strive to improve the quality of teaching.

Meanwhile, with the deepening of globalization, English has become an important language tool for universities to train international talents nowadays. English has also become an important subject in college foreign language teaching. But often under the same teaching resources and learning environment, different students' English learning effect is very different. This is partly due to individual differences and emotional factors. Learning motivation varies by individual differences. At the same time, learning motivation is also an important part of emotional factors. Among the many emotional factors that affect English learning, English learning motivation has concerned by domestic and foreign researchers. In the past few decades, the study on foreign language teaching has been developing in a diversified way. And researchers gradually focus their attention on language learners. They have come to an agreement that language learners' individual differences have a great effect on foreign language acquisition. Individual differences include language aptitude, gender, learning motivation, learning strategies,etc. Wu et al (1993:158)pointed out that "since learning motivation is a meaningful predictor of academic achievement, it is worth for us to further discuss and cultivate students' positive learning motivation". So in this paper, the author chooses one of these key factors to investigate, namely, English learning motivation.

\section{LITERATURE REVIEW}

\subsection{Major transfer}

\subsubsection{Definition}

"The Dictionary of Higher Education "(1993:332) defines" transfer major "as the transfer from the original department to other departments for special reasons, such as additional expertise, physiological limitations, etc. The Dictionary of Education Management(1997:234) defines the transfer major as a student from one major to another. The Dictionary of Education(1991:219) holds that the transfer major is the abbreviation for the transfer of students from the original major to another major. Liu
(2010) believes that "transfer major ", from the student level, is that after they entering the university if they are not satisfied with the original major, can re-select their favorite major; from the university level, it refers to the professional adjustment work of freshmen according to students' wishes. This paper adopts Wei's (2014) definition of major transfer: "most college students in our country choose the major they will study when they fill in the college entrance examination. But in the process of learning, some students find they are not satisfied with their major. At that time, according to their own wishes and through the school's policies and procedures for the transfer of major, they will choose transfer one major to another new major, that is, major transfer ".

\subsubsection{Major transferring in college students at abroad}

Foreign college students have considerable autonomy in transferring majors, and the school's operation of transfer procedures is also very simple and flexible. For example, Harvard University has always been responsive to students' needs for major transferring. "Applicants for major transferring submitted in the last semester of graduation can also be approved (Harvard College, 2005)."Similarly, if students from California University at Berkeley have a desire to transfer their majors, they only need to submit an application form signed by the tutor of department, and the teaching management system will automatically transfer the student's

major. In addition, at California Institute of Technology, undergraduates can transfer majors if they meet the graduation requirements of the relevant professional courses or get the approval of the relevant professional representatives.

It can be seen that foreign universities have adopted a very flexible approach to students' requests for major transferring. Therefore, scholars from various countries (Peter, 2011; Micceri, 2001; Jorge, 2000) present a unique academic research with different focuses on transferring major. While in foreign countries, the flexibility of the higher education major selection system has caused foreign scholars to focus on the factors affecting the transfer of majors. Therefore, the author will discuss the reasons of transferring majors in the next part.

2.1.3 Major transferring in college students at 


\section{home}

The major transferring of undergraduates in Chinese universities started in September 2002 at Fudan University. On September 1, 2005, the Ministry of Education issued the Regulations on the Management of Students in Ordinary Higher Education Institutions, which stated: "Students can apply for transfer major according to the regulations of the school. The transfer of majors is approved by the school. The school changes according to the development and the society's demand for talents. With the consent of the student, the major of the student can be adjusted appropriately if necessary."

\subsection{The reasons of transferring majors}

There are many reasons for college students to transfer majors. According to the research of domestic scholars, I analyze them from the perspective of students, and summarize them from two aspects: internal and external reasons:

Internal reasons:

(1) Personal interest; a big reason the students apply for major transfer is that they have no interest in the chosen major. If students do not raise any interest in selected major, they will not have learning enthusiasm and are easy to have the idea of changing the major (Wang Shumin, 2011; Zhou Xuanyu, etc. 2016). (2)Disease or physiological defects; (Zhang Yin et al. 2011). (3)Blindness before choosing a major; this blindness is mainly reflected in two aspects: one is students cannot position their interests, ability and expertise accurately; the other is have no clear understanding of the main courses and training objectives of their major. The ambiguity of these two aspects may lead to the mismatch of students ' own interests, ability and professional requirements, and is also a potential factor for students to change their major (Li Aiguo, 2009; Sun Yu, 2016; Steve,2005). (4)Enhancement of self-consciousness; (Adamek Raymend J,1966; Wu, 2013). (5)Poor adaptation; Some students cannot quickly adapt to the current professional environment due to their personality characteristics and other reasons, which is the common idea of transferring majors (Warren J.R,1961; Chen Yan, 2007). (6)Followed blindly; (Jin Jun, 2012).

External reasons:

(1)Parents 'intervention; (Li Aiguo, 2009). (2) Be influenced by Lao; (Liu Xiaolian, Liu Kang, 2011). (3)
Employment orientation; current social employment orientation also has a great impact on students ' majors. Some curriculum settings are very old, cannot keep up with the needs of current times, so students are more willing to transfer to high employment majors and relatively new courses (Liu Juan, 2010; Malgwi Charles A,2005). (4) Tuition; major transfer is linked to the financial conditions of students, especially those from poor areas, whose pressure forcing them to be willing to transfer from high learning costs (such as arts) to low learning costs (Wang Shumin, 2011). (5) Majors; if students are transferred to other majors due to insufficient scores, they will choose to transfer to other majors (Li Aiguo, 2009; Marphy,2000).

\subsection{Summary}

To sum up, through induction and analysis, the reasons of college students' transfer major is mainly related to students' interests, personal professional adaptability, consideration of employment prospects, unreasonable professional setting and family economy.

Looking at the above domestic and foreign scholars' discussion on the subject of undergraduate transfer,we can see that from the theoretical basic research of the transfer system to the analysis of the reasons and influencing factors of the transfer system, the researchers explored the practical topic of transfer. Whether it is from the perspective of the school or students, there is no lack of reasonable and detailed argumentation in the existing research.

However, in the process of searching the literature, most of them are universal studies, there are very few studies involving the transfer to a specific major. After investigation, it is found that the current phenomenon of college students transferring to English majors is relatively common. In May 2020, the Guide to Teaching English majors in Colleges (hereinafter referred to as the Guide) was published. The guide states the aims of English major, (1) Good basic English language skills;(2) Basic knowledge of English literature, language and culture;(3)Good humanities and scientific literacy;(4)Strong speculative skills;(5) Cross-cultural communication skills. So the students who transfer to English major will face lots of difficulties, their academic performance, grades and learning motivation may be 
changed. But few studies concerned about their comparison before and after transferring majors.

\section{FOREIGN LANGUAGE LEARNING MOTIVATION}

\subsubsection{The definition of foreign language learning motivation}

There are many emotional factors that affect foreign language learning, and it is one of the most important factors. The study of foreign language learning motivation began in the late 1950s (Gardner \& Lambert). As a pioneer, the famous Canadian applied linguist Gardner and his colleague Lambert published a paper entitled "Motivational Variables in Second Language Acquisition" in the Canadian Psychology as early as 1959. Since then, Gardner (1985) has continued to engage in related research on foreign language learning motivation from the perspective of social psychology. He defines the motivation of individuals to learn foreign languages into four dimensions: goals, effortful behavior, a desire to attain the goal, and favourable attitude towards the activity in question. Through research, Gardner and Lambert (1985) designed and modified a language learning motivation measurement tool, namely the Attitude/Motivation Test Battery (AMTB), which has become the most authoritative foreign language learning motivation measurement tool.

\subsubsection{Classification of foreign language learning motivation}

Since the study of foreign language learning motivation based on social psychology, scholars have different views on the classification of it. So far, there are three main categories of it. First, according to the foreign language learners' different learning purposes. Gardner \& Lambert (1959) proposed the classical dichotomy of foreign language learning motivation: integrative motivation and instrumental motivation. Second, according to the source of motivation of foreign language learners. J.Bruner (1983) identified the importance of internal motivation and believed that children should be liberated from the incentive punishment mechanism when learning language, because although the incentive punishment mechanism works quickly, it is also easy to lead to bad learning habits. He encourages children to learn independently, identify with new discoveries from within, and use it as a positive reward. Since then, E.L.Deci\&R.M.Ryan (1985) have clearly divided learning motivation into extrinsic motivation and intrinsic motivation, and pointed out that learners should actively cultivate intrinsic motivation. Do not advocate learning by teachers to encourage punishment and other extrinsic motivation. Both scholars believe that intrinsic learning motivation can promote better classroom learning effect than extrinsic motivation. Under the influence of affirming intrinsic learning motivation, the concept of self-determination is put forward for the first time, which lays a theoretical foundation for the development of self-determination.Third, entering the new century, Brown (2000) proposed a new three-point method: global motivation, situational motivation and task motivation.

But all of the classifications are related, they have connections more or less, and in this part, four kinds of classification put forward by domestic and foreign scholars will be introduced.

\subsubsection{Integrative Motivation and Instrumental}

\section{Motivation}

Gardner \& Lambert (1972) classified learning motivation into two dimensions: one is integrative motivation, the other is instrumental motivation. Integrative motivation means that language learners are enthusiastic about learning the target language so that they can be one member of the target language community or adapt to the culture of target language. Instrumental motivation refers to language learners' utilitarian intention in the process of target language learning, such as, applying for a satisfactory job, achieving high scores in the target language examinations, or obtaining social status, etc. Integrative motivation is a reflection of language learners' great interest in not only the target language they are learning but also the culture within the target language community. In comparison with integrative motivation, language learners in instrumental motivation are more passive and practical in learning target language. And they show less interest in the culture of target language community.

\subsubsection{Intrinsic Motivation and Extrinsic}

\section{Motivation}

Deci \& Ryan(1985) proposed the difference between intrinsic and extrinsic motivation.According to them, 
"intrinsic motivation involves the activities with no apparent reward except the activity itself, and extrinsic motivation relates to some anticipation of a reward from outside and beyond the self".

Intrinsic motivation means that language learners desire to obtain sense of satisfaction and happiness from the process of learning the target language, while extrinsic motivation means that language learners learn the target language for achieving certain purposes. Interest is the most important factor for Deci \& Ryan(1985) to distinguish intrinsic motivation and extrinsic motivation. Language learners who hold intrinsic motivation are usually highly motivated in their learning process. They tend to be self-governed and passionate in learning the target language. Language learners with extrinsic motivation are likely to pursue external rewards rather than show interest in the target language. According to the characteristics of intrinsic and extrinsic motivation, conclusions can be drawn that the former one from learners' inner desire and the latter one is usually influenced by many external factors.

3.2.2.3 Instrumental motivation, cultural motivation, and situational motivation

Considering that Gardner's classic model (Gardner, 1985) and its expansions were originated in contexts different from EFL in China, Gao Yihonget al (2003) conducted one of the largest scale investigations of Chinese college students,aiming to induct the basic motivation types of Chinese students, finally, seven types of motivation were finally 1) intrinsic interest; 2) immediate achievement; 3) going abroad; 4) learning situation; 5) social responsibility;6) individual development; and 7) information medium.

Seven types of motivation can be further generalized into three broader constructs: instrumental motivation, cultural motivation, and situational motivation. Instrumental motivation refers to the using of target language to attain specific goals, including information medium, individual development, and immediate achievement. Cultural motivation involves the interests and concerns for culture, subsuming intrinsic interest and social responsibility which pertain to target-language culture and native-language culture respectively. It is similar to Gardner 's integrative motivation, but with the difference that integrative motivation only focuses on target-language culture. Going abroad had both "integrative" and "instrumental" elements. Immediate achievement and social responsibility might be typical features of English learners in the Chinese EFL context. Social responsibility is both "cultural" and "instrumental" in nature. Situational motivation concerns the influence of micro learning situation on learners.

\subsubsection{Deep Motivation and Surface Motivation}

Wen (2001) classifies motivation into surface motivation and deep motivation based on the levels of motivation. Surface motivation is the second language learning for the surface material incentives, such as getting a diploma or a job. Deep motivation refers to the second language learning for the non-material stimulations, such as learning the second language for interests or knowledge.

Although the classifications of motivation are different from their perspectives and criterion, these categories all have some connections with each other. Integrative motivation, cultural motivation and deep motivation are all connected with the learners' affections and other internally deep factors while the instrumental motivation, situation motivation and surface motivation are all associated with the external factors. The classification is as follows:

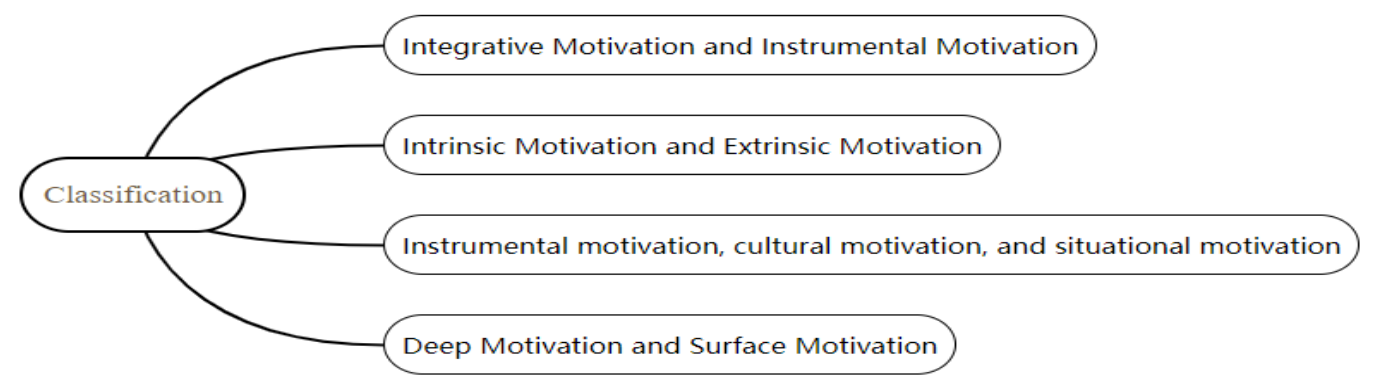




\subsubsection{Related studies on foreign language learning motivation}

\subsubsection{Related studies at abroad}

Ryoko(2018) aims to understand the motivation types and learning experiences of Japanese as a foreign language learners(JFL) in New Zealand, where foreign language learning is neither required nor widely valued, and where JFL learner numbers have declined at universities. This study draws a different picture to previous English as foreign language motivation research about future self-images, showing that different target languages and diverse reasons for learning should be considered in analyzing second language motivation.

Kazuya's study(2017) set out to examine the role of learner motivation in second language speech learning in English-as-a-Foreign-Language classrooms. He found that these students likely showed a strong motivation to study English for their future career development as a vague and long-term goal, as well as a high degree of concern for improving comprehensibility, grammatical accuracy and complexity.

María(2011) describes a mixed-reality experience for learning Spanish as a foreign language, which takes place in a virtual world that mirrors a boulevard in Madrid. The results of their evaluation show positive effects on student motivation and improvement in learning outcomes.

$\mathrm{Koga}(2009)$ investigated the dynamicity of motivation, anxiety and cooperativeness of Japanese college students during 15 weeks' English course study. The research aimed to figure out whether individual difference variables can be developed or weaken in classroom contexts. From the results, English learning motivation didn't change significantly during this period, while anxiety and cooperativeness showed an obvious change.

The above review of recent literature of foreign language learning motivation draws the following conclusions. First of all, the research perspective needs to be further expanded. The mainstream research in foreign language learning motivation is still focused on the study of foreign language motivation, but the research perspective of foreign language learning motivation is not broad enough, such as the language types need to be expanded, and the effectiveness of model construction needs to be verified by further empirical research.Secondly, theoretical research and empirical research should keep together. The field of foreign language motivation research is mainly empirical research, and less attention is paid to longitudinal literature review.

\subsubsection{Related studies at home}

Wei (2013) explored the relationship between second language motivation self-system and autonomous learning behavior of 316 non-English majors, and concluded the conclusion. In foreign language teaching, teachers should guide students to build an ideal second language self by creating a good teaching environment and strengthening the training of autonomous learning strategies, so as to help students form a positive concept of foreign language learning and improve students' autonomy in foreign language learning.

Zhou Yan et al (2011) made an follow-up survey on the English learning motivation development of Seniors in college. Results indicated that individual development motivation and information media motivation were the dominant driving forcesin English learning for college seniors. Approaching graduation, intrinsic interest motivation and and going abroad motivation would significantly increase.

Guo (2009) conducted an empirical study on the relationship between motivation, achievement and gender in English learning for graduate students. 86 boys and 48 girls majored in English wereselected to participate in the research and Wen Qiufang's (2000) motivation questionnaire wasemployed. Then obtained three conclusions. First, on the whole, the deep motivation of the subjects was stronger than the surface motivation, and the two had a statistically negative correlation; the English entrance scores of the subjects were significantly negatively correlated with the surface learning motivation; second, the English scores of the high and low groups were significantly different; third, girls' English scores are higher than boys', their surface motivation is weaker than boys', and their differences reach a significant level. Based on the above three conclusions, the paper gives corresponding suggestion.

$\mathrm{Du}$ (2011) made an investigation to examine the relationship between non-English majors' English learning motivation and learning achievements. The questionnaire 
adopted in the research was Gardner's motivation questionnaire. Results indicated that intrinsic motivation was positively correlated with learning achievements, especially interest and sense of achievement motivation.

Domestic foreign language learning motivation research lasted more than 30 years. It has been found that the main characteristics of foreign language learning motivation in China in recent years are summarized as follows: first, the number of literature studies has maintained a dynamic growth; second, the research perspective focuses on subject integration; third, the research methods are mainly empirical research, supplemented by theoretical research; fourth, the subjects include foreign language learners of different backgrounds and ages; fifth, the research samples show a large and refined development trend; Sixth, the research state is transition from the static study of cross-section to the dynamic study of tracing.

\section{SUMMARY}

Existing literature shows that most scholars specialize in the study motivation of non-English majors ( Du, 2011, etc.), some scholars study the learning motivation of English majors (Mai, 2005,etc.), and some scholars study the overall undergraduate students English learning motivation(Liu \& Gao, 2012, etc.). But there are few studies on English learning motivation of college students who have transferred majors, when talk about the learning motivation on college transfer majors in English, the studies are more less, too. Although transfer students are a small group, they should be paid equally attention to. So on the basis, in the future, I will focus on a study in which subjects are college transfer majors in English, to explore the English learning motivation among them in different grade, and discuss the differences before and after transferring major.

\section{REFERENCES}

[1] Adamek Raymond J, Goudy Willis J. Identification. Sex, And Change in College Major[J]. Sociology of Education;1966:83-199.

[2] Cohen. J. and Hanno. D.M. An analysis of underlying constructs affecting the choice of accounting as a major[J] Issues in Accounting Education, Fall 1993:236.
[3] Deci, E.L \& Ryan, R. M. Intrinsic Motivation and Self Determination in Human Behavior [M]. New York: Plenum Press, 1985.

[4] Gao YiHong, Zhao Yuan, Cheng Ying, etc. English learning motivation type of Chinese undergraduates [ J]. Modern Foreign Language, 2003 (01): 28 - 38

[5] Gardner, R. C. \& Lambert, W. E Motivational variables in second language acquisition [J]. Canadian Journal of Psychology, 1959(4): 266-272

[6] Gardner, R. C. Social Psychology and Language L earning: The Role of Attitude and Motivation [M]. London Edward Aronld, 1985.

[7] Gardner, R.C. \& W. Lambert. Attitudes and Motivation in Second Language Learning [M]. Rowley Mass: Newbury House Publishers, 1972.

[8] Guo Jidong. Relations between Motivation and Achievement and Gender in Graduate English [ J]. Foreign Language Community, 2009 (05): 42 - 49

[9] Harvard College. Handbook for Student 2005-2006. Cambridge: Harvard University.2005:29-30.

[10] He Zijing. Reason Analysis and Measures of College Students Transferring Majors [ J]. China Electric Power Education, 2014, 09: 153 - 154

[11] Jin Jun. Research on the Transfer Motivation and Impact Factors of College Students [ J] Jiangsu Science and Technology Information, 2012, 01: 38 - 39.

[12] Kazuya Satio, Jean-Marc Dewaele, Keiko Hanzawa, A Longitudinal Investigation of the Relationship Between Motivation and Late Second Language Speech Learning in Classroom Settings [J]. Language and Speech, 2017,60:2-19

[13] Koga, T. Dynamicity of motivation, anxiety and cooperativeness in a semester course [J]. System, 2009,38:72-184.

[14] Li Aiguo. Analysis and Thinking of College Students Transferring Majors [ J]. Adult Education in China, 2009, 23: $35-36$

[15] Li Jing, Meng Yanli. An Empirical Study of the Motivation of English Learning Students [ J]. Heilongjiang Higher Education Research, 2013, 31 (07): 181 - 184

[16] Li Jiongying, Liu Penghui. An Empirical Study on the Motivation of Foreign Language Learning for Chinese undergraduates [ J].Journal of $\mathrm{Xi}^{\prime}$ an Foreign Studies University, 2017, 25 (02): 63 - 68

[17] Liu Juan. Current Status and Measures of Undergraduate 
Major Transfer in Chinese Universities [ D]. Zhejiang Normal University, 2010

[18] Ma Guanghui. Effect of Learning motivation and degree of effort on Foreign Language Learning Performance [ J]. Journal of PLA Foreign Language College, 2005 (04): 37 - 41

[19] Micceri Ted, Change your major and double your graduation chances.[C]Paper presented at the Annual Meeting of the Association for Institutional Research (Long Beach CA June 3-6, 2001

[20] Peter Arcidiacono V. Joseph Hotz Songman Kang: Modeling College Major Choices using Elicited easures of Expectations and Counterfactuals, February 16, 2011.

[21] Ryokode Burgh-Hirabe1, Motivation to learn Japanese as a foreign language in an English speaking country: An exploratory case study in New Zealand [J]. System, 2019,80 : 95-106

[22] Strasser, Sandra E, CeyhunOzgur and David L.Schroeder: Selecting a Business College Major: An Analysis of Criteria and Choice using the Analytical Hierarchy Process[J].Mid-American Journal of Business,Fall 2002:52-54

[23] Wang Shumin. Analysis of Undergraduate Motivation in Transferring Majors[J]. China Science and Education Innovation, 2011, 19: 156

[24] Wang Xiaomin, Zhang Wenzhong. Analysis of Foreign Language learning motivation in China $[\mathrm{J}]$. Foreign Language Community, 2005 (4): 58 - 65

[25] Wang Youcai. Analysis and Thinking on the Major Transfer of College Students [ J]. Technology Information, 2011, 35: 380

[26] Warren. J.R. Self-concept, occupational role expectation and change in major college[J], Journal of Counseling Psychology,1961:64-169.

[27] Wen Qiufang. Rules and characteristics of English learners ' motivation, ideas and strategy [ D]. Foreign Language and Foreign Language Teaching, 2001, 2

[28] Wu Guangjun. Research on Translation Learning Motivation of English College Students [ J]. Foreign Language Teaching, 2019, 40 (02): $66-70$

[29] Zhang Yin, Liu Dayu, Wang Wei. Thoughts on the phenomenon of undergraduate major transfer [ J]. Education and Teaching Research 211.02: 71 - 74

[30] Zhou Yan, Gao Hong, Zang Qing. Development of Senior English Learning Motivations — Track Research of five
College Students [ J].Foreign Language Teaching and Studies, 2011, 43 (02): 251 - $260320-321$ 